\title{
AVALIAÇÃO DO DESENVOLVIMENTO DE DIFERENTES TAMANHOS DE MUDAS MICROPROPAGADAS DE ABACAXIZEIRO, APÓS ACLIMATAÇÃO ${ }^{1}$
}

\author{
SÁVIO DA SILVA BERILLI ${ }^{2}$, ALMY JUNIOR CORDEIRO DE CARVALHO 3 , \\ SILVIO DE JESUS FREITAS ${ }^{4}$, DENÍLSON COELHO FARIA ${ }^{5}$, CLAUDIA SALES MARINHO ${ }^{6}$
}

RESUMO - A micropropagação de plantas é extremamente útil na multiplicação de novas cultivares em larga escala. O abacaxizeiro 'Vitória' é uma cultivar com a importante característica de ser resistente à fusariose. Após cultivo in vitro e aclimatização, é possível produzir mudas de diferentes tamanhos, entretanto um tamanho-padrão tem sido utilizado para comercialização. O uso de mudas de diferentes estádios de crescimento, após a aclimatização, pode interferir na qualidade final das mudas para o plantio no campo. O objetivo deste trabalho foi avaliar o efeito dos diferentes tamanhos de mudas do abacaxizeiro 'Vitória', após aclimatização, na qualidade dessas após o período de aclimatação. Foram selecionadas mudas micropropagadas do abacaxizeiro 'Vitoria', aclimatizadas em casa de vegetação com diferentes tamanhos, e estas foram plantadas em canteiros a céu aberto para aclimatação, por um período de 150 dias. Foi utilizado o delineamento experimental em blocos casualizados, em arranjo fatorial $5 \times 2$, correspondentes a cinco períodos de aclimatização das mudas $(30 ; 60 ; 90 ; 120$ e 150 dias) e a duas épocas de avaliação (início e aos 150 dias da aclimatação). Os tratamentos foram avaliados em relação ao número de folhas, área foliar, altura da planta, diâmetro de roseta, comprimento da folha mais desenvolvida, massa seca e massa fresca da parte aérea. Para as condições deste experimento, verificou-se que mudas com 60; 90; 120 e 150 dias após aclimatização apresentam condições para aclimatação.

Termos para indexação: Ananas comosus var. comosus, cultivar Vitória, cultivo in vitro, viveiro, fusariose.

\section{EVALUATION OF THE DEVELOPMENT OF DIFFERENT SIZES OF MICROPROPAGATED SEEEDLINGS OF PINEAPPLE TREE, AFTER ACCLIMATIZATION}

\begin{abstract}
The micropropagation of plants is extremely useful in the multiplication of new cultivars in wide scale. The pineapple tree 'Vitória' is a cultivar with the important characteristic of being resistant to the fusariosis. After in vitro cultivation and acclimatization it is possible to produce seedlings of different sizes, however a standard size has been used for marketing. The use of seedlings of different stages of growth, after the acclimatization, can interfere in the final quality of the seedlings for the planting in the field. This study was carried out to evaluate the effect of the different sizes of seedlings of pineapple tree 'Vitória', after acclimatization, and their qualities after the acclimatizing period. Micropropagated seedlings of pineapple tree 'Vitoria' were selected, acclimatized in greenhouse with different sizes and these were planted in stonemason open sky for acclimatization, for a period of 150 days. It was used randomized complete block design, factorial scheme $5 \times 2$, corresponding to five acclimatizing periods of the seedlings $(30,60,90,120$ and 150 days) and the two times of evaluation (at the beginning and at 150 days of acclimatization). The treatments were valued regarding to the number of leaves, leaf area, height of the plant, diameter of rosette, length of the most developed leaf, dry mass and fresh mass of the air part. For the conditions of this experiment, it was verified that seedlings with 60,90 120, and 150 days after acclimatization present conditions for acclimatizing.
\end{abstract}

Index terms: Ananas comosus var. comosus; cultivar Vitória; cultivation in vitro; nursery; fusariosis.

\footnotetext{
'(Trabalho 013-10). Recebido em: 04-01-2010. Aceito para publicação em: 28-07-2010.

${ }^{2}$ Eng. Agr. DS. Professor, Instituto Federal do Espírito Santo - Campus Itapina - Rodovia BR-259, Km 70 - Zona Rural - Caixa postal 256, CEP 29709-910 - Colatina - ES, (27) 3723-1246, E-mail: berilli@gmail.com

${ }^{3}$ Eng. Agr. DS. Professor, Universidade Estadual do Norte Fluminense, Avenida Alberto Lamego, 2000, Sala 116 P4, Horto, CEP28013-602, Campos dos Goytacazes-RJ, E-mail: almy@uenf.br

${ }^{4}$ Doutor em Produção Vegetal, Universidade Estadual do Norte Fluminense, Avenida Alberto Lamego, 2000, Sala 116-P4, Horto, CEP- 28013-602, Campos dos Goytacazes-RJ, (22) 2739 7097, E-mail: freitas-sj@hotmail.com

${ }^{5}$ Eng. Agr. Mestrado em Produção Vegetal, Universidade Estadual do Norte Fluminense, Avenida Alberto Lamego, 2000, Sala 116 P4, Horto, CEP- 28013-602, Campos dos Goytacazes-RJ, (22) 2739 7097, E-mail: coelhofaria@gmail.com

${ }^{6}$ Eng. Agr. DS, Professor, Universidade Estadual do Norte Fluminense, Avenida Alberto Lamego, 2000, Sala 116 P4, Horto, CEP28013-602, Campos dos Goytacazes-RJ, E-mail: marinho@uenf.br
} 


\section{INTRODUÇÃO}

A suscetibilidade da abacaxicultura brasileira à fusariose limita a produção comercial em todo o território nacional. O desenvolvimento de novas cultivares que apresentem resistência a essa doença, tornou-se objetivo prioritário de programas de melhoramento da cultura. A cultivar Vitória, resistente à fusariose e lançada em 2006, no Estado do Espírito Santo, constitui alternativa para controlar os problemas com essa doença (VENTURA et al., 2006). Juntamente com novas cultivares, vem a necessidade de novas pesquisas em toda a cadeia produtiva, com o intuito de melhorar todo o sistema de produção, desde a propagação até a obtenção final de frutos de alta qualidade.

Os termos aclimatização e aclimatação são muitas vezes confundidos, porém a correta conotação de aclimatização refere-se à transferência de plântulas in vitro para um ambiente protegido, como em casas de vegetação com telados (ambiente controlado), sendo esse um processo basicamente artificial. A aclimatação representa a fase seguinte do processo de adaptação que ocorre, essencialmente, em ambiente natural (GUERRA;NODARI, 2006).

Alguns estudos, baseados na pré-aclimatização de plântulas ainda in vitro, visam à antecipação de alterações morfológicas e fisiológicas que minimizem o impacto decorrente da transição para casas de vegetação, tais como o aumento da densidade de fluxo luminoso, baixa umidade relativa do ambiente, variações da temperatura, dentre outros (KODYM; ARIAS, 1999; CALVETE et al., 2002; ALBERT, 2004). Tais estudos vêm sendo realizados para superar dificuldades de adaptação do meio de cultivo para a fase de aclimatização, pois as folhas das plantas in vitro são geralmente finas, tenras e fotossinteticamente pouco ativas, por isso mal adaptadas às condições ex vitro.

A otimização na fase de aclimatização também tem sido procurada por meio do uso de substratos adequados (MOREIRA, 2001; ALBERT, 2004), associações com fungos micorrizicos e bactérias diazotróficas (WEBER et al., 2003; BALDOTTO, 2009), uso de reguladores de crescimento (COELHO, 2005; CATUNDA et al., 2008), equilíbrio da adubação (MOREIRA, 2001; COELHO et al., 2007), dentre outros. Todos esses estudos visam, em última instância, à produção de mudas de qualidade, em menor tempo e a menores custos.

Da mesma forma que estudos vêm sendo realizados com o intuito de minimizar o impacto na aclimatização, esforços também têm sido feitos para reduzir o impacto da transferência da casa de vegetação para o viveiro no campo (BREGONCI et al., 2008).

Mudas de abacaxizeiro micropropagadas são comercializadas após aclimatização com altura aproximada de 6 a $7 \mathrm{~cm}$ e massa fresca de parte aérea de 2 a 3 g. A fase de aclimatação ainda é necessária para que tamanho e rusticidade da muda, para plantio definitivo no campo, sejam atingidos. Reinhardt e Cunha (1999) recomendaram a altura a partir de 25 $\mathrm{cm}$, como adequada para o plantio definitivo das mudas obtidas por secções de caule. Coelho et al. (2007) obteviveram mudas de abacaxizeiro provenientes de seccionamento de caule, com $200 \mathrm{~g}$, em período próximo a nove meses de aclimatação.

Alguns trabalhos foram realizados para obtenção de mudas convencionais de qualidade em condições de campo, como no caso de mudas do tipo filhote, submetidas a diferentes níveis de desbastes ou manejo das cevas (REINHARDT et al., 2003; LIMA et al., 2002), no entanto todos relacionados à produção convencional de mudas.

Apesar de muitos estudos indicarem diferentes formas para obtenção de rápido crescimento na fase de aclimatização e, consequentemente, um encurtamento dessa fase, pouco se sabe sobre os efeitos destes tratamentos na aclimatação ou na fase de plantio definitivo. Sendo assim, o objetivo deste trabalho foi avaliar diferentes tamanhos de mudas micropropagadas e aclimatizadas do abacaxizeiro 'Vitória' no desenvolvimento destas após aclimatação.

\section{MATERIAL E MÉTODOS}

O local do experimento foi na Estação Experimental da Empresa de Pesquisa Agropecuária do Estado do Rio de Janeiro (PESAGRO - Rio), município de Campos dos Goytacazes, região norte do Estado do Rio de Janeiro, cujas coordenadas geográficas são: $21^{0} 48^{\prime}$ de latitude sul, e $41^{\circ} 20^{\prime}$ de longitude oeste, e altitude de $11 \mathrm{~m}$. A região é classificada como de clima quente e úmido (AW). A amplitude térmica anual no mês mais frio é $21{ }^{\circ} \mathrm{C}$, e a do mês mais quente, 27 ${ }^{\circ} \mathrm{C}$. Os dados de temperatura durante a realização do experimento podem ser observados na Tabela 1.

Inicialmente, as mudas foram adquiridas da biofábrica (Biomudas, 2009), a qual utilizou o substrato comercial Plantmax Hortaliças ${ }^{\circledR}$ e bandejas de poliestileno de 200 células. A composição química média do substrato é apresentada a seguir: $\mathrm{pH}$ em água de 4,9; 9,72 $\mathrm{g} \mathrm{kg}^{-1}$ de $\mathrm{N} ; 9,36 \mathrm{~g} \mathrm{~kg}^{-1}$ de $\mathrm{P} ; 5,16$ $\mathrm{g} \mathrm{kg}^{-1}$ de K; $19 \mathrm{~g} \mathrm{~kg}^{-1}$ de Ca; $21 \mathrm{~g} \mathrm{~kg}^{-1}$ de $\mathrm{Mg} ; 3,39 \mathrm{~g}$ $\mathrm{kg}^{-1}$ de S; $11.430 \mathrm{mg} \mathrm{kg}^{-1}$ de Fe; $26 \mathrm{mg} \mathrm{kg}^{-1}$ de $\mathrm{Cu}$; $62 \mathrm{mg} \mathrm{kg}^{-1}$ de $\mathrm{Zn}$; e $220 \mathrm{mg} \mathrm{kg}^{-1}$ de Mn. O solo do 
local onde foi implantado o experimento é, segundo a classificação brasileira de solos, um Neossolo flúvico Tb (Embrapa, 1999). As características físicas são de $75 \%$ de fração areia, $19 \%$ de silte e $6 \%$ de argila, e as características químicas como se segue: $\mathrm{pH}$ de 5,4; $15 \mathrm{mg} \mathrm{kg}^{-1}$ de P; $46 \mathrm{mg} \mathrm{kg}^{-1}$ de $\mathrm{K} ; 1 \mathrm{cmol}_{\mathrm{c}} \mathrm{dm}^{-3}$ de $\mathrm{Ca} ; 0,8 \mathrm{cmol}_{\mathrm{c}} \mathrm{dm}^{-3} \mathrm{de} \mathrm{Mg} ; 0,3 \mathrm{cmol}_{\mathrm{c}} \mathrm{dm}^{-3} \mathrm{de}$ $\mathrm{Al} ; 0,05 \mathrm{cmol}_{\mathrm{c}} \mathrm{dm}^{-3}$ de $\mathrm{Na}$; e para os micronutrientes $\mathrm{Fe}, \mathrm{Cu}, \mathrm{Zn}$ e $\mathrm{Mn}$ foi verificado 46,8; 1,5; 1,8 e $29,1 \mathrm{mg} \mathrm{dm}^{-3}$, respectivamente. Para essas análises, foi utilizado o extrator Carolina do Norte. As análises foram feitas no laboratório de análises químicas da Universidade Federal Rural do Rio de Janeiro (UFRRJ), Câmpus Dr. Leonel Miranda, localizado no município de Campos dos Goytacazes - RJ.

Foi utilizado o abacaxizeiro da cultivar 'Vitória', o qual foi plantado em canteiros individuais e irrigado de acordo com a demanda evapotranspirométrica (REGO FILHO, 2002). O espaçamento adotado foi de $15 \mathrm{~cm}$ x $15 \mathrm{~cm}$ entre plantas, tendo sido efetuada uma adubação foliar por semana em todos os tratamentos, na dosagem de $0,5 \%$ de ureia e $0,5 \%$ de cloreto de potássio com regador manual, na quantidade de cinco litros de solução por $\mathrm{m}^{2}$. No momento do plantio nos canteiros, foram adicionados $3 \mathrm{~g}$ de $\mathrm{P}_{2} \mathrm{O}_{5}$, por cova, na forma de superfosfato simples.

O delineamento utilizado foi em blocos casualizados, com três repetições, em arranjo fatorial $5 \times 2$, composto de cinco estádios de desenvolvimento das mudas micropropagadas e aclimatizadas (estádio 1 com 30 dias, estádio 2 com 60 dias, estádio 3 com 90 dias, estádio 4 com 120 dias e estádio 5 com 150 dias de aclimatização) e duas épocas de avaliação (início e aos 150 dias da aclimatação). Cada estádio correspondeu a um período diferente, de aclimatização das mudas durante a aclimatização. Em casa de vegetação, entre junho e dezembro de 2007, na empresa Biomudas, localizada no município de Venda Nova do Imigrante - ES. Em cada estádio, as mudas apresentaram tamanhos, com variação no número de folhas, área foliar, altura da planta, diâmetro da planta, comprimento da folha mais desenvolvida, massa fresca e massa seca da parte aérea (Tabelas 2 e 3 ).

O experimento foi conduzido no período de dezembro de 2007 a maio de 2008. As avaliações foram feitas no início e no final do experimento, com base em amostra de três mudas, para cada parcela constituída por 15 plantas.

O número de folhas foi obtido destacandose todas as folhas da planta. A área foliar foi obtida através do aparelho Li-cor ${ }^{\circledR}$ modelo 3100 .

As avaliações biométricas das plantas foram realizadas utilizando réguas graduadas. As medições de altura foram realizadas da base da planta até o ponto mais alto das folhas, sem alterar a estrutura das plantas. $\mathrm{O}$ diâmetro da roseta foi medido entre as maiores folhas opostas. O comprimento da folha mais desenvolvida foi medido após sua retirada.

Para análise da massa fresca e da massa seca, foram utilizadas balanças de precisão. Após a medição da massa fresca da parte aérea, o material vegetal foi acondicionado em sacos de papel e colocado para secar, utilizando-se de estufa de circulação forçada de ar, à temperatura de $70^{\circ} \mathrm{C}$, por 72 horas, para a obtenção da massa seca.

Para todas as características avaliadas, foi calculada a relação de crescimento entre as duas épocas de avaliação, dividindo-se os valores médios das características avaliadas ao final do experimento pelos valores médios das características iniciais.

A taxa de pegamento das mudas foi determinado descontando-se as perdas, em cada parcela, ao término do experimento. Os dados foram submetidos a análises de variância, pelo teste $\mathrm{F}(\mathrm{p}<0,01)$, e as médias, comparadas pelo teste de Tukey $(\mathrm{p}<$ $0,05)$.

\section{RESULTADOS E DISCUSSÃO}

No início do experimento, foram verificadas diferenças entre os estádios para todas as variáveis $(\mathrm{p} \leq 0,05)$. Algumas variáveis foram semelhantes entre alguns dos estádios de aclimatização, mas somente a área foliar e a massa fresca da parte aérea diferiram entre cada um dos tratamentos (Tabelas 3 e 4$)$.

A aclimatização de mudas micropropagadas da cv. 'Vitória' foi avaliada por Baldotto (2009) em resposta à inoculação com bactérias promotoras de crescimento, aos 150 dias de aclimatização. Esse autor observou, por planta, 17 a 19 folhas, 13 a $15 \mathrm{~cm}$ de diâmetro de roseta e 125 a $223 \mathrm{~cm}^{2}$ de área foliar. Esses valores diferem dos encontrados no presente trabalho para mudas, aos 150 dias de aclimatização (Tabela 2). Tais diferenças podem ocorrer, em função principalmente da temperatura no interior das casas de vegetação e dos diferentes tratos culturais.

As diferenças iniciais entre os tratamentos, apesar de estatisticamente pouco expressivas, determinaram variações significativas $(p<0,05)$ para todas as variáveis avaliadas no final do período de aclimatação (Tabelas 3 e 4), o que demonstra uma amplificação das diferenças no decorrer do período da aclimatação e a importância da escolha do tamanho de uma muda aclimatizada a ser transplantada para viveiros. 
Mudas com as características do estádio 3 vêm sendo comercializadas por biofábricas para posterior aclimatação pelo produtor. Como não foram observadas diferenças significativas entre o número de folhas, a altura de plantas e o diâmetro da roseta após 150 dias de aclimatação, entre as mudas provenientes dos estádios $2 ; 3$ e 4 , sugere-se que mudas destes estádios poderiam estar aptas à comercialização.

Plantas provenientes dos estádios $2 ; 3$ e 4 apresentaram, após aclimatação, valores médios de altura muito próximos, em torno de $22 \mathrm{~cm}$ (Tabela 2). Essa informação é importante para as biofábricas produtoras de mudas de abacaxi, uma vez que a altura das plantas é um dos principais fatores na decisão da retirada das mudas da casa de vegetação para a comercialização. A possibilidade de comercialização das mudas desses diferentes estádios representa economia de tempo e de recursos, sem perda de qualidade. As outras características, como o diâmetro da roseta e o número de folhas, seguiram esse mesmo padrão de resposta $(\mathrm{p}<0,05)$.

Trabalho realizado por Silva et al. (1995) indica que, quanto maior a rusticidade das mudas de diferentes espécies micropropagadas, melhor é o seu desempenho durante a aclimatação. Em contrapartida, resultados encontrados por Bregonci et al. (2008) demonstram que mudas de abacaxi micropropagadas e aclimatizadas por diferentes períodos podem ou não diferir em algumas características de crescimento ao fim do processo de aclimatação, concordando com os resultados deste experimento.

As mudas do estádio 1, inicialmente com 5,4 $\mathrm{cm}$ de altura, atingiram, aos 150 dias de aclimatação, menores médias de altura, em torno de $14,9 \mathrm{~cm}$, sendo estas consideradas inadequadas para o plantio no campo. Segundo Albert (2004), no período de aclimatização, alterações morfológicas e fisiológicas ocorrem e possibilitam uma transição bem-sucedida.

As maiores médias da área foliar, da altura da planta, do diâmetro da roseta, comprimento da folha mais desenvolvida e da massa seca das mudas foram verificadas no estádio 5 , e as menores, no estádio 1. Não foram verificadas diferenças significativas entre plantas oriundas dos estádios 2 e 3 após 150 dias de aclimatação.

O pegamento das mudas dos estádios 2; 3 e 4 foi de $95 \%$, enquanto no estádio 1 foi de $85 \%$ e no estádio 5 de 100\%. Bregonci et al. (2008) constataram pegamento próximo a $94 \%$ para mudas aclimatadas da cv. Gold sem prévia aclimatização. Apesar de o pegamento das mudas do 'Vitória' (mesmo este tendo passado por 30 dias de aclimatização) ter sido inferior ao do 'Gold', diferenças entre fatores genéticos e ambientais entre os experimentos devem ser levadas em consideração.

Apesar de as plantas vindas do estádio 5 apresentarem maiores médias para as características de crescimento e melhor índice de pegamento, o tempo necessário para que as mudas atinjam esses valores é longo e, além disso, estas são consideradas refugo na produção comercial. Entretanto, com referência à qualidade das mudas, nada impede que essas sejam comercializadas.

Os resultados deste experimento indicam que os produtores de mudas micropropagadas podem adotar maior flexibilidade na comercialização, não ficando limitados apenas a um estádio-padrão de venda (estádio 3), como é praticado atualmente. Isso pode vir a reduzir o preço final das mudas.

Bregonci et al. (2008) avaliaram a aclimatação de mudas micropropagadas do abacaxi 'Gold', imediatamente após a retirada do meio de cultivo in vitro, e com períodos de aclimatização variando entre 30 e 150 dias. Os referidos autores observaram que, após aclimatação, as mudas transplantadas imediatamente após a retirada do meio in vitro, apresentaram área foliar, massa seca da parte aérea, massa seca da raiz e comprimento da raiz de mudas inferiores aos demais tratamentos, corroborando os resultados desse experimento. No presente trabalho, as mudas com menor tempo de aclimatização (30 dias) apresentaram características de crescimento inferiores às outras mudas com maiores períodos de aclimatização.

Considerando que os estádios de desenvolvimento 1 e 5 são extremos não desejados pelos produtores de mudas micropropagadas de abacaxi, observamos que os estádios 2; 3 e 4 não diferiram em características importantes de crescimento, como altura da planta e diâmetro da roseta, ao fim do período de aclimatação. Tais características são decisivas na retirada das mudas da casa de vegetação, demonstrando que, para as condições deste experimento, há a viabilidade de comercialização em qualquer um destes estádios.

A Tabela 4 mostra que os estádios 2; 3 e 4 seguem um padrão inverso entre estádios das mudas e o ganho de crescimento, para as características do número de folha, altura de planta e comprimento da folha mais desenvolvida, ou seja, quanto menor o estádio, maior é o ganho de crescimento para essas características.

O estádio 2 (60 dias de aclimatização) apresentou, em praticamente todas as características avaliadas, as maiores médias de ganho de crescimento com relação aos outros estádios, sobretudo com relação ao estádio 1. Resultados divergentes foram encontrados por Bregonci et al. (2008), trabalho no qual mudas 
micropropagadas do abacaxi 'Gold', aclimatizadas por um período de 30 dias (equivalente ao estádio 1 deste experimento), apresentaram o maior ganho de crescimento em relação a mudas com intervalos maiores (60 a 150 dias) de aclimatização, após 150 dias de aclimatação. Nesse caso, devem-se atribuir tais diferenças nos resultados às condições de cultivo e ao genótipo utilizado nos diferentes trabalhos.

Apesar de os estádios 1 e 2 estarem próximos no seu desenvolvimento fisiologicamente, o estádio 1 não acompanhou o ritmo de crescimento do estádio 2 , nem dos demais estádios, o que lhe conferiu tamanho inadequado ao final da aclimatação.

Informações sobre todas as etapas da cadeia produtiva das mudas micropropagadas de abacaxizeiro (cultura de tecidos - aclimatização - aclimatação) são importantes para a produção de maiores quantidades de mudas de qualidade. Ressalta-se, portanto, que mais estudos devem ser realizados no campo, após plantio definitivo, com o intuito de observar as consequências dos tratamentos adotados em etapas anteriores.

TABELA 1 - Valores médios mensais de temperatura máxima (T-máxima), mínima (T-mínima), média (Tmédia), em ${ }^{\circ} \mathrm{C}$, umidade relativa (UR em \%) e precipitação mensal (P em mm), no período de dezembro de 2007 a maio de 2008.

\begin{tabular}{lcccccc}
\hline & Dez./2007 & Jan./2008 & Fev./2008 & Mar./2008 & Abr./2008 & Maio/2008 \\
\hline T-máxima ( $\left.{ }^{\circ} \mathbf{C}\right)$ & 31,0 & 29,5 & 30,9 & 31,2 & 30,7 & 28,2 \\
T-mínima $\left({ }^{\circ} \mathbf{C}\right)$ & 21,2 & 20,9 & 21,6 & 21,4 & 20,7 & 16,6 \\
T-média $\left({ }^{\circ} \mathbf{C}\right)$ & 26,7 & 25,9 & 26,9 & 26,4 & 26,1 & 22,9 \\
UR (\%) & 72,0 & 74,0 & 73,0 & 72,0 & 73,0 & 68,0 \\
$\mathbf{P ( m m )}$ & 116,4 & 241,4 & 146,5 & 66,7 & 243,4 & 6,2 \\
\hline
\end{tabular}

Dados obtidos na estação meteorológica da Uenf e Pesagro-RJ.

TABELA 2 - Médias do número de folhas, área foliar $\left(\mathrm{cm}^{2}\right)$, altura e diâmetro de roseta $(\mathrm{cm})$ de mudas micropropagadas do abacaxizeiro cv. Vitória provindas de diferentes períodos de aclimatização, no início e após 150 dias de aclimatação.

\begin{tabular}{ccccccccc}
\hline \multirow{2}{*}{$\begin{array}{c}\text { Estádios de } \\
\text { aclimatização } \\
(\text { dias })\end{array}$} & \multicolumn{2}{c}{$\mathrm{N}^{\mathrm{o}}$ de folhas } & \multicolumn{2}{c}{$\begin{array}{c}\text { Área foliar } \\
\left(\mathrm{cm}^{2}\right)\end{array}$} & \multicolumn{2}{c}{$\begin{array}{c}\text { Altura da planta } \\
(\mathrm{cm})\end{array}$} & \multicolumn{2}{c}{$\begin{array}{c}\text { Diâmetro de roseta } \\
(\mathrm{cm})\end{array}$} \\
\cline { 2 - 9 } & Início & Final & Início & Final & Início & Final & Início & Final \\
\hline 30 & $10,2 \mathrm{Ab}$ & $16,6 \mathrm{Bb}$ & $20 \mathrm{Ae}$ & $216 \mathrm{Bd}$ & $5,4 \mathrm{Ad}$ & $14,9 \mathrm{Bc}$ & $3,50 \mathrm{Ad}$ & $32,7 \mathrm{Bc}$ \\
60 & $10,8 \mathrm{Ab}$ & $22,4 \mathrm{Ba}$ & $26 \mathrm{Ad}$ & $582 \mathrm{Bc}$ & $5,7 \mathrm{Ad}$ & $22,0 \mathrm{Bb}$ & $5,50 \mathrm{Ac}$ & $40,9 \mathrm{Bb}$ \\
90 & $11,0 \mathrm{Ab}$ & $21,7 \mathrm{Ba}$ & $37 \mathrm{Ac}$ & $606 \mathrm{Bc}$ & $6,8 \mathrm{Ac}$ & $22,2 \mathrm{Bb}$ & $8,13 \mathrm{Ab}$ & $41,4 \mathrm{Bb}$ \\
120 & $12,3 \mathrm{Aa}$ & $24,0 \mathrm{Ba}$ & $53 \mathrm{Ab}$ & $890 \mathrm{Bb}$ & $9,7 \mathrm{Ab}$ & $22,4 \mathrm{Bb}$ & $8,31 \mathrm{Ab}$ & $42,3 \mathrm{Bb}$ \\
150 & $12,5 \mathrm{Aa}$ & $24,5 \mathrm{Ba}$ & $81 \mathrm{Aa}$ & $1164 \mathrm{Ba}$ & $11,2 \mathrm{Aa}$ & $27,5 \mathrm{Ba}$ & $11,4 \mathrm{Aa}$ & $50,7 \mathrm{Ba}$ \\
\hline Média & 11,4 & 21,5 & 43,49 & 697 & 7,79 & 22,2 & 7,53 & 39,5 \\
CV $(\%)$ & 6,68 & 12,3 & 7,47 & 25,18 & 6,0 & 21,0 & 2,03 & 18,2 \\
\hline
\end{tabular}

Valores com letras maiúsculas e minúsculas repetidas nas linhas e nas colunas, respectivamente, não diferem entre si, pelo teste Tukey, a $5 \%$ de probabilidade. 
TABELA 3 - Médias do comprimento da folha mais desenvolvida, massa fresca (MF) e massa seca (MS) da parte aérea de mudas micropropagadas do abacaxizeiro cv. Vitória provindas de diferentes períodos de aclimatização, no início e após 150 dias de aclimatação.

\begin{tabular}{ccccccc}
\hline $\begin{array}{c}\text { Estádios de } \\
\text { aclimatização } \\
(\text { dias })\end{array}$ & $\begin{array}{c}\text { Comprimento da folha } \\
\text { mais desenvolvida } \\
(\mathrm{cm})\end{array}$ & \multicolumn{2}{c}{$\begin{array}{c}\text { MS } \\
(\mathrm{g})\end{array}$} & \multicolumn{2}{c}{$\begin{array}{c}\text { MF } \\
(\mathrm{g})\end{array}$} \\
\cline { 2 - 7 } & Início & Final & Início & Final & Início & Final \\
\hline 30 & $5,3 \mathrm{Ad}$ & $14,2 \mathrm{Bd}$ & $0,09 \mathrm{Ad}$ & $1,82 \mathrm{Bd}$ & $1,07 \mathrm{Ae}$ & $19,9 \mathrm{Bc}$ \\
60 & $6,1 \mathrm{Ad}$ & $19,8 \mathrm{Bc}$ & $0,13 \mathrm{Ad}$ & $6,48 \mathrm{Bc}$ & $1,71 \mathrm{Ad}$ & $69,2 \mathrm{Bbc}$ \\
90 & $7,4 \mathrm{Ac}$ & $22,6 \mathrm{Bc}$ & $0,35 \mathrm{Ac}$ & $6,74 \mathrm{Bc}$ & $2,79 \mathrm{Ac}$ & $74,9 \mathrm{Bb}$ \\
120 & $9,8 \mathrm{Ab}$ & $26,0 \mathrm{Bb}$ & $0,54 \mathrm{Ab}$ & $11,41 \mathrm{Bb}$ & $4,76 \mathrm{Ab}$ & $130,0 \mathrm{Ba}$ \\
150 & $12,3 \mathrm{Aa}$ & $28,3 \mathrm{Ba}$ & $0,93 \mathrm{Aa}$ & $13,74 \mathrm{Ba}$ & $7,61 \mathrm{Aa}$ & $165,4 \mathrm{Ba}$ \\
\hline Média & 8,2 & 22,2 & 0,41 & 7,65 & 3,59 & 87,31 \\
CV $(\%)$ & 7,6 & 21,23 & 10,73 & 26,74 & 13,6 & 27,12 \\
\hline
\end{tabular}

Valores com letras maiúsculas e minúsculas repetidas nas linhas e nas colunas, respectivamente, não diferem entre si, pelo teste Tukey, a $5 \%$ de probabilidade.

TABELA 4 - Relação de crescimento entre as duas épocas de avaliação (início e após 150 dias de aclimatação) dos valores médios do número de folhas, área foliar, altura, diâmetro, comprimento da folha mais desenvolvida, massa seca (MS) e massa fresca (MF) de mudas micropropagadas do abacaxizeiro cv. Vitória provindas de diferentes períodos de aclimatização.

\begin{tabular}{ccccccccc}
\hline $\begin{array}{c}\text { Estádios de } \\
\text { aclimatização } \\
\text { (dias) }\end{array}$ & $\mathrm{N}^{\mathrm{o}}$ de folhas & Área foliar & Altura & $\begin{array}{c}\text { Diâmetro } \\
\text { de roseta }\end{array}$ & $\begin{array}{c}\text { Comprimento da folha } \\
\text { mais desenvolvida }\end{array}$ & MF & MS \\
\hline 30 & $1,62 \mathrm{~b}$ & $10,67 \mathrm{~b}$ & $2,74 \mathrm{a}$ & $9,35 \mathrm{a}$ & $2,65 \mathrm{ab}$ & $18,7 \mathrm{~b}$ & $21,2 \mathrm{~b}$ \\
60 & $2,07 \mathrm{a}$ & $22,23 \mathrm{a}$ & $3,83 \mathrm{ab}$ & $7,43 \mathrm{~b}$ & $3,27 \mathrm{a}$ & $40,4 \mathrm{a}$ & $48,8 \mathrm{a}$ \\
90 & $1,97 \mathrm{ab}$ & $16,42 \mathrm{ab}$ & $3,24 \mathrm{ab}$ & $5,09 \mathrm{c}$ & $3,06 \mathrm{ab}$ & $26,9 \mathrm{ab}$ & $19,3 \mathrm{~b}$ \\
120 & $1,95 \mathrm{ab}$ & $17,01 \mathrm{ab}$ & $2,31 \mathrm{~b}$ & $5,09 \mathrm{c}$ & $2,64 \mathrm{ab}$ & $27,3 \mathrm{ab}$ & $21,2 \mathrm{~b}$ \\
150 & $1,95 \mathrm{ab}$ & $14,32 \mathrm{~b}$ & $2,44 \mathrm{~b}$ & $4,45 \mathrm{c}$ & $2,31 \mathrm{~b}$ & $21,7 \mathrm{~b}$ & $14,7 \mathrm{~b}$ \\
\hline Média & 1,92 & 16,73 & 2,85 & 6,42 & 2,82 & 26,6 & 26,3 \\
CV $(\%)$ & 16,3 & 39,3 & 23,34 & 23,53 & 22.10 & 37,3 & 38,3 \\
\hline
\end{tabular}

*letras minúsculas repetidas nas colunas não diferem entre si, pelo teste Tukey, a 5\% de probabilidade.

\section{CONCLUSÃO}

Variações no tamanho inicial das mudas micropropagadas e aclimatizadas do abacaxizeiro 'Vitória' influenciam no tamanho final da muda após o processo de aclimatação. Nas condições deste experimento apresentam maior tamanho final de mudas que permanecem 150 dias na aclimatização. No entanto, mudas com 60; 90 e 120 dias apresentam o maior desenvolvimento relativo ao tamanho inicial, mostrando também condições para aclimatação.

\section{REFERÊNCIAS}

ALBERT, L. H. B. Aspectos morfoanatômicos de mudas de abacaxizeiro 'Smooth Cayenne' micropropagadas. 2004. 54 f. Tese (Doutorado em Fitotecnia) - Universidade Federal de Lavras, Lavras, 2004.

BALDOTTO, L. E. B. Estrutura e fisiologia da interação entre bactérias diazotróficas endofíticas e epifíticas com abacaxizeiro cultivar 'Vitória' durante a aclimatização. 2009. 120 f. Tese (Doutorado em Melhoramento de Plantas) - Universidade Estadual do Norte Fluminense, Campos dos Goytacazes, 2009. 
BIOMUDAS - Laboratório de biotecnologia: venda nova do imigrante. Espírito Santo, 2009. Disponível em: $<$ http://www.biomudas.com.br $>$. Acesso em: 01 out. 2009.

BREGONCI, S. I.; REIS, E. S.; ALMEIDA, G. D.; BRUM, V. J.; ZUCOLOTO, M. Avaliação do crescimento foliar e radicular de mudas micropropagadas do abacaxizeiro cv. Gold em aclimatação. Idesia, Chile, v. 26, n. 3, p. 87-96, 2008.

CABRAL, J. R. S.; MATOS, A. P. Imperial, nova cultivar de abacaxi. Cruz das Almas : Embrapa CNPM, 2005. 4p.

CALVETE, E. O.; AZEVEDO, M.; BORDIGNON, M. H.; SUZIN, M. Análises anatômicas e da biomassa em plantas de morangueiro cultivadas in vitro e ex vitro. Horticultura Brasileira, Brasília, v. 20, n. 4, p. 649-653. 2002.

CATUNDA, P. H. A.; MARINHO, C. S.; GOMES, M. M. A.; CARVALHO, A. J. C. Brassinosteroide e susbstratos na aclimatização do abacaxizeiro 'Imperial'. Acta Scientiarum Agronomy, Maringá, v. 30, n. 3, p. 345-352, 2008.

COELHO, R. I. Clonagem do abacaxizeiro a partir de coroas e secções de caule tratadas com reguladores de crescimento e fertilizantes químicos. 2005. 114 f. Tese (Doutorado em Produção Vegetal) - Universidade Estadual do Norte Fluminense, Campos dos Goytacazes, 2005.

COELHO, R. I.; CARVALHO, A. J. C.; MARINHO, C. S.; LOPES, J. C.; PESSANHA, P. G. O. Resposta à adubação com ureia, cloreto de potássio e ácido bórico em mudas do abacaxizeiro 'Smooth Cayenne'. Revista Brasileira de Fruticultura, Jaboticabal, v. 29, n. 1, p. 161-165, 2007.

EMBRAPA. Sistema brasileiro de classificação de solos. Rio de Janeiro: Embrapa Solos, 1999.

GUERRA, M. P.; NODARI, R. O. Material didático de apoio à disciplina de Biotecnologia, Santa Catarina: Universidade Federal de Santa Catarina. 2006. Disponível em: <http://www.cca.ufsc.br/lfdgv/ Apostila.htm>. Acesso em: 27 out. 2009.
KODYM, A.; ARIAS, Z. F. J. Natural light as an alternative light source for the in vitro culture of banana (Musa acuminata cv. Grande Naine). Plant Cell, Tissue and Organ Culture, The Hague, v. 55, n. 2, p. 141-145, 1999.

LIMA, V. P.; REINHARDT, D. H.; COSTA, J. A. Desbaste de mudas tipo filhote do abacaxi cv. Pérola - 2. Análise de crescimento e correlações. Revista Brasileira de Fruticultura, Jaboticabal, v. 24, n. 1, p. 101-107, 2002.

MOREIRA, M. A. Produção e aclimatização de mudas micropropagadas de abacaxizeiro Ananas comosus (L) Merril cv. Pérola. 2001. 81 f. Tese (Doutorado em produção vegetal)-Universidade Federal de Lavras, Lavras, 2001.

REGO FILHO, L. M. Resposta do abacaxizeiro pérola a diferentes lâminas de irrigação no Norte Fluminense. 2002. 150 f. Tese (Doutorado em Produção vegetal) - Universidade Estadual do Norte Fluminense, Campos dos Goytacazes, 2002.

REINHARDT, D.H.; CUNHA, G. A. P. Métodos de propagação. In: CUNHA, G. A. P.; CABRAL, J. R. S.; SOUZA, L. F. S. O abacaxizeiro: cultivo, agroindústria e economia. Brasília: Embrapa, 1999. p. 33.

REINHARDT, D. H.; SOUZA, A. P. M.; CALDAS, R. C.; AlCÂNTARA, J. P.; AlmEIDA, A. A. Management of slips and its effect on growth and production of 'Pérola' pineapple plants. Revista Brasileira de Fruticultura, Jaboticabal, v. 25, n. 2, p. 248-252, 2003.

SILVA, A. T.; PASQUAL, M.; ISHIDA, J. S.; ANTUNES, L. E. C. Aclimatação de plantas provenientes de cultura in vitro. Pesquisa Agropecuária Brasileira Brasília, v. 30, n. 1, p. 49-53, 1995.

VENTURA, J. A.; CABRAL, J. R. S.; MATOS, A. P.; COSTA, H. Nova cultivar de abacaxi resistente à fusariose. Vitória(ES): Incaper, 2006. (Documento, 148).

WEBER, O. B.; CORREIA, D.; ROCHA, M. W.; ALVEZ, G. C.; OLIVEIRA, E. M.; SÁ, E. G. Resposta de plantas micropropagadas de abacaxizeiro à inoculação de bactérias diazotróficas em casa de vegetação. Revista Agropecuária Brasileira, Brasília, v. 38, n. 12, p. 1419-1426, 2003. 